\title{
Prognostic impact of standard laboratory values on outcome in patients with sudden sensorineural hearing loss
}

\author{
Julia Wittig ${ }^{1}$, Claus Wittekindt ${ }^{1,2}$, Michael Kiehntopf ${ }^{3}$ and Orlando Guntinas-Lichius ${ }^{1 *}$
}

\begin{abstract}
Background: Aim of the present study was to evaluate prognostic factors, in particular standard laboratory parameters, for better outcome after idiopathic sudden sensorineural hearing loss (SSNHL).

Methods: Using a retrospective review, 173 patients were included presenting between 2006 and 2009 with unilateral SSNHL, $\geq 30 \mathrm{~dB}$ bone conduction in three succeeding frequencies between 0.125 to $8 \mathrm{kHz}$ in pure tone audiometry (PTA), and a time interval between first symptoms and diagnostics $\leq 4$ weeks. Hearing gain of $<10 \mathrm{~dB}$ versus $\geq 10 \mathrm{~dB}$ in the affected ear in 6PTA values was the primary outcome criterion. Univariate and multivariate statistical tests were used to analyze predictors for better outcome.

Results: The initial hearing loss was $50.6 \pm 27.2 \mathrm{~dB}$. The absolute hearing gain was $15.6 \pm 20.1 \mathrm{~dB}$. Eighty-one patients (47\%) had a final hearing gain of $\geq 10 \mathrm{~dB}$. Low-frequency hearing loss $(p<0.0001)$; start of inpatient treatment $<4$ days after onset ( $p=0.018)$; first SSNHL (versus recurrent SSNHL, $p=0.001$ ); initial hearing loss $\geq 60 \mathrm{~dB}(p<0.0001)$; an initial quick value lower than the reference values $(p=0.040)$; and a pretherapeutic hyperfibrinogenemia $(p=0.007)$ were significantly correlated to better outcome ( $\geq 10 \mathrm{~dB}$ absolute hearing gain). Multivariate analysis revealed that first SSNHL ( $p=0.004)$, start of treatment $<4$ days after onset $(p=0.015)$, initial hearing loss $\geq 60 \mathrm{~dB}(p=0.001)$, and hyperfibrinogenemia ( $p=0.032$ ) were independent prognostic factors for better hearing recovery.

Conclusion: Better hearing gain in patients with hyperfibrinogenemia might be explained by the rheological properties of the applied therapy and supports the hypothesis that SSNHL is caused in part by vascular factors.
\end{abstract}

Keywords: Serology, Blood value, Outcome, Prognostic marker, Hearing loss

\section{Background}

Idiopathic sudden sensorineural hearing loss [SSNHL) is defined as unexplained unilateral sensorineural hearing loss of $30 \mathrm{~dB}$ HL or greater over 3 continuous frequencies with onset over a period of less than 72 hours and with no marked vestibular symptoms [1]. SSNHL has an estimated incidence between 160 and 400 per 100,000 persons per year, i.e. much higher than assumed in older studies [2,3]. The causes of SSNHL are speculative and probably multifactorial [4]. Cardiovascular disease, cigarette smoking, and hypertension appear to be the most common risk factors associated with SSNHL $[2,4]$.

\footnotetext{
*Correspondence: orlando.guntinas@med.uni-jena.de

'Department of Otorhinolaryngology, Jena University Hospital, Lessingstrasse 2, Jena D-07740, Germany

Full list of author information is available at the end of the article
}

Advanced age, severe hearing loss, heredity, audiogram shape, and presence of vertigo seem to be significant negative prognostic factors $[4,5]$. Most studies analyzing prognostic factors do not evaluate if the therapy itself applied to the patients with SSNHL has an influence on these prognostic factors. Furthermore, most studies include a variety of therapy regimes and sometimes also patients who did not receive any therapy. This makes it difficult to interpret the concrete role of the discovered risk factors. In a recent study using a uniform standardized therapy consisting of carbogen inhalation and oral prednisone, the prognostic factors for better recovery were severity of initial hearing loss, presence of vertigo, time between onset and treatment, the hearing of the other ear, and the audiogram shape [5]. 
Although especially vascular factors are constantly discussed to be related to the etiology of SSNHL, it is surprising that so far the prognostic impact of the entire range of routine laboratory values has not been evaluated systematically. Therefore, the present study investigated whether patients with SSNHL and its comorbidity also influence routine pretherapeutic laboratory values and whether these values have prognostic influence on hearing recovery after a standardized combined glucocorticoid and rheological therapeutic regime.

\section{Methods}

\section{Patients}

A standardized retrospective analysis was performed in the Department of Otorhinolaryngology of the University Hospital Jena in Germany. The study protocol was approved by the institutional ethics committee of the Friedrich-Schiller University, Jena, Germany. All adult patients who were treated for unilateral idiopathic sudden sensorineural hearing loss between 2006 and 2009 were included in the database for this study. Prerequisite was a differential diagnostic evaluation excluding a specific etiology (like head trauma, vestibular schwannoma) explaining the sudden hearing loss. All patients received a brainstem electrical response audiometry (BERA). If the BERA was pathologic, a magnetic resonance imaging (MRI) of the head and cerebellopontine angle was performed. Further inclusion criterion was that at least 2 pure-tone audiograms were available: the first at presentation prior to initiation of therapy, and a second after therapy. If more than one follow-up audiogram was available, the last audiogram was taken for analysis. Follow-up audiometry was stopped when no further hearing improvement was seen. Exclusion criteria were: Hearing loss $<30 \mathrm{~dB}$ bone conduction in three succeeding frequencies between 0.125 to $8 \mathrm{kHz}$ as revealed by pure tone audiometry; time interval between first symptoms and diagnostics $>4$ weeks; acute bilateral hearing loss; combination with acute vestibular hypofunction (excluded by caloric vestibular testing); history of chronic ear disease (like otosclerosis, chronic otitis media, Menière's disease). A search of the patients' electronic charts was performed, and the following variables were obtained: age, sex, smoking behavior (yes/no), Charlson comorbidity index [6], presentation of a metabolic syndrome (if patient had $\geq 3$ of the following diseases: diabetes mellitus, hypertension, adiposity, atherosclerosis, gout, hyperlipidemia), presentation of cardiovascular risk factors (if patients had at least 1 of the following diseases/history of diseases: vein thrombosis, apoplexy, cardiac infarction, diabetes mellitus, hypertension, hyperlipidemia) and tinnitus (yes/no).

All patients were hospitalized. Treatment followed the German guideline for sudden idiopathic sensorineural hearing loss as 1-week combination of glucocorticoid and rheological therapy with pentoxifyllin [6,7]. Mainly, a tapered course of oral corticosteroids is regarded as standard treatment [1].

\section{Audiometric assessment}

Audiometric evaluation included air conduction and bone conduction thresholds on the affected and the contralateral side revealed by pure tone audiometry. The pure tone average (PTA) was calculated from the results of bone conduction at $0.25,0.5,1,2,4$, and $6 \mathrm{kHz}$ (6PTA). The severity of the hearing loss was described exactly according to Cvorovic et al. [5] as 1) mild, PTA of 15 to $39 \mathrm{~dB}$; 2) moderate, PTA of 40 to $59 \mathrm{~dB}$; 3) severe, PTA of 60 to $79 \mathrm{~dB}$; 4) profound, PTA of 80 to $100 \mathrm{~dB}$; and 5) deaf, PTA of greater than $100 \mathrm{~dB}$ [5]. Furthermore, the pattern of the initial audiogram was categorized into 1 of 4 types [5]: Low frequencies were defined as $0.5 \mathrm{kHz}$ or less, midfrequencies as greater than 0.5 and $2 \mathrm{kHz}$ or greater, and high frequencies as greater than 2 and $8 \mathrm{kHz}$ or less. The following types of audiograms were defined: 1) low frequency, ascending, greater than $15 \mathrm{~dB} \mathrm{HL}$ from the poorer low-frequency thresholds to the higher frequencies; 2) midfrequency, U-shaped, greater than $15 \mathrm{~dB}$ HL difference between the poorest thresholds in the midfrequencies and those at higher and lower frequencies; 3) high frequency, descending, greater than $15 \mathrm{~dB}$ HL difference between the mean of 0.5 and $1 \mathrm{kHz}$ and the mean of 4 and $8 \mathrm{kHz} ; 4$ ) flat, less than $15 \mathrm{~dB}$ HL difference between the mean of $0.25-, 0.5-\mathrm{kHz}$ thresholds, the mean of 1 and $2 \mathrm{kHz}$, and the mean of 4 and $8 \mathrm{kHz}$; and 5) total deafness, hearing loss of $100 \mathrm{~dB}$ or more in $0.5,1,2$, and $4 \mathrm{kHz}$.

Hearing gain was expressed as absolute hearing gain ( $\triangle 6 \mathrm{PTA}$; $\mathrm{dB}$ values) from initial PTA minus $\mathrm{dB}$ values from final PTA. If a negative value was calculated, the hearing gain was set to zero. For calculation of the relative hearing gain, the absolute gain $\triangle \mathrm{PTA}$ was divided by the initial PTA. In order to calculate the relative hearing gain in relation to the contralateral ear, $\triangle \mathrm{PTA}$ was divided by the initial PTA minus PTA on the contralateral side [8].

\section{Laboratory values}

The assessment of pretreatment laboratory values included: Hematologic profile with red blood cells, hemoglobin, mean corpuscular volume (MCV), mean corpuscular hemoglobin $(\mathrm{MCH})$, mean corpuscular hemoglobin concentration (MCHC), white blood cells, and platelets; glucose; electrolytes covered sodium, potassium, calcium, urea and creatinine values; the inflammation parameter C-reactive protein (CRP); lipid metabolism with cholesterol, low density lipoprotein (LDL), high density lipoprotein (HDL), LDL/HDL index, and finally 
the coagulation parameters Quick value, activated partial thromboplastin time (aPTT), and fibrinogen. The blood samples were taken before start of treatment to rule out an influence of the treatment on the laboratory values. The normal reference values for all laboratory parameters are given in Table 1. Most parameters are pathological if lower or higher than the reference range, but some are only pathological if lower than normal range (e.g. Quick value) or higher than the normal range (e.g. CRP).

\section{Statistical analysis}

If not indicated otherwise, data are presented with mean values \pm standard deviation (SD). All statistical analyses were performed using IBM SPSS, version 20.0. Primary outcome criterion was absolute hearing gain $(\triangle 6 \mathrm{PTA})$ dichotomized into two groups of patients $(<10 \mathrm{~dB}$ versus $\geq 10 \mathrm{~dB})$.
The chi-square test was used to compare subgroups for ordinal parameters (e.g. gender, side, laboratory parameters dichotomized into normal versus pathologic values. The non-parametric Mann-Whitney U-test was used to compare subgroups for continuous parameters (e.g. age). Prognostic factors associated with higher frequency of hearing gain $\geq 10 \mathrm{~dB}$ with a probability value of $p<0.05$ were included in a binary ( $<10 \mathrm{~dB}$ versus $\geq 10 \mathrm{~dB}$ hearing gain) logistic regression analysis. Nominal $p$ values of two-tailed tests are reported. The significance level was set at $p<0.05$.

\section{Results}

\section{Patients' and disease characteristics}

One hundred and seventy-three (173) patients were included into the study and constituted the database for this study. Patients' characteristics and details on SSNHL are given in Table 2. The median age was 64 years. The

Table 1 Blood values at time of diagnosis $(n=173)$

\begin{tabular}{|c|c|c|c|c|c|c|}
\hline Parameter & Mean (SD) & Median & Min. & Max. & Normal range & Patients outside normal range (\%) \\
\hline $\mathrm{aPTT}(\mathrm{sec})$ & $30.3(5.8)$ & 29 & 20 & 56 & $26-36$ & $39(23)$ \\
\hline Quick (\%) & $95.4(24.7)$ & 100.5 & 9 & 128 & $70-130$ & $17(10)$ \\
\hline Fibrinogen $(\mathrm{g} / \mathrm{l})$ & $3.1(1)$ & 3 & 1.3 & 8.7 & $1.8-3.5$ & $43(25)$ \\
\hline Red-cell count (Tptl/I) women & $4.6(0.3)$ & 4.6 & 3.5 & 5.5 & $4.1-5.1$ & $9(5)$ \\
\hline Red-cell count (Tptl/I) men & $4.9(0.5)$ & 4.9 & 3.7 & 7.2 & $4.5-5.9$ & $19(11)$ \\
\hline Hemoglobin $(\mathrm{mmol} / \mathrm{l})$ women & $8.5(0.6)$ & 8.5 & 7 & 10 & 7.6-9.5 & $8(5)$ \\
\hline Hemoglobin $(\mathrm{mmol} / \mathrm{l})$ men & $9.1(0.8)$ & 9.2 & 6.1 & 10.7 & 8.7-10.9 & $21(12)$ \\
\hline Hematocrit women & $0.41(0.03)$ & 0.4 & 0.34 & 0.48 & $0.35-0.45$ & $5(3)$ \\
\hline Hematocrit men & $0.43(0.03)$ & 0.43 & 0.32 & 0.49 & $0.36-0.48$ & $4(2)$ \\
\hline White-cell count $(/ \mu l)$ & $8462.4(3102.6)$ & 7600 & 1100 & 20900 & $4400-11300$ & $28(16)$ \\
\hline Platelet count (Gpt/l) & $250(65.7)$ & 245 & 89 & 610 & $150-360$ & $9(5)$ \\
\hline $\mathrm{MCH}$ & $1.86(0.1)$ & 1.9 & 1.2 & 2.12 & $1.74-2.05$ & $21(21)$ \\
\hline $\mathrm{MCHC}$ & $21.1(0.6)$ & 21.1 & 18.7 & 22.5 & $19.7-22.1$ & $7(4)$ \\
\hline MCV & $88.2(4.8)$ & 88 & 63 & 99 & $80-96$ & $8(5)$ \\
\hline Glucose $(\mathrm{mmol} / \mathrm{l})$ & $6.7(2.3)$ & 5.9 & 3.6 & 17.4 & 3.9-5.8 & $91(53)$ \\
\hline Sodium (mmol/l) & $140.8(2.7)$ & 141 & 130 & 149 & $135-145$ & $10(6)$ \\
\hline Potassium (mmol/l) & $3.9(0.4)$ & 3.9 & 2.6 & 5.3 & $3.3-4.5$ & $23(13)$ \\
\hline Calcium $(\mathrm{mmol} / \mathrm{l})$ & $2.4(0.1)$ & 2.4 & 2 & 2.9 & $2.2-2.6$ & $10(6)$ \\
\hline Urea $(\mathrm{mmol} / \mathrm{l})$ & $6.1(2.1)$ & 5.8 & 2.2 & 17.4 & $2.6-7.5$ & $32(19)$ \\
\hline Creatinine $(I \mathrm{~mol} / \mathrm{l})$ women & $80(17.4)$ & 78 & 50 & 189 & $58-96$ & $6(4)$ \\
\hline Creatinine $(\mathrm{Imol} / \mathrm{I})$ men & $96.3(21.3)$ & 92 & 57 & 182 & $72-127$ & $14(8)$ \\
\hline C-reactive protein $(\mathrm{mg} / \mathrm{l})$ & $4.7(15.3)$ & 1.9 & 1.9 & 188.2 & $\leqq 7.5$ & $12(7)$ \\
\hline Cholesterol (mmol/l) & $5.6(1.1)$ & 5.6 & 3.1 & 9.3 & $\leqq 5.2$ & $65(38)$ \\
\hline $\mathrm{LDL}(\mathrm{mmol} / \mathrm{l})$ & $3.3(1)$ & 3.3 & 1.2 & 6.1 & $\leqq 4.1$ & $22(13)$ \\
\hline $\mathrm{HDL}(\mathrm{mmol} / \mathrm{l})$ & $1.4(0.4)$ & 1.3 & 0.8 & 2.8 & $\geqq 1.0$ & $8(5)$ \\
\hline LDL/HDL & $2.5(0.9)$ & 2.4 & 0.6 & 5.3 & $\leqq 4.1$ & $4(2)$ \\
\hline Triglycerides (mmol/l) & $1.81(1.1)$ & 1.4 & 0.4 & 7 & $\leqq 1.7$ & $39(23)$ \\
\hline
\end{tabular}

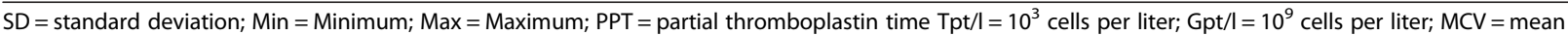
corpuscular volume, $\mathrm{MCH}=$ mean corpuscular hemoglobin, $\mathrm{MCHC}=$ mean corpuscular hemoglobin concentration; $\mathrm{LDL}=$ low-density lipoprotein; $\mathrm{HDL}=$ high-density lipoprotein. 
Table 2 Patients' characteristics $(n=173)$

\begin{tabular}{|c|c|}
\hline & Number of patients (\%) \\
\hline \multicolumn{2}{|l|}{ Gender } \\
\hline Female & $82(47)$ \\
\hline Male & $91(53)$ \\
\hline \multicolumn{2}{|l|}{ Affected side } \\
\hline Left & $91(53)$ \\
\hline Right & $82(47)$ \\
\hline First SSNHL & $124(72)$ \\
\hline Recurrent SSNHL & $49(28)$ \\
\hline \multicolumn{2}{|l|}{ Audiogram pattern } \\
\hline Low-frequency & $9(5)$ \\
\hline Mid-frequency & $12(7)$ \\
\hline High-frequency & $63(36)$ \\
\hline Flat & $55(32)$ \\
\hline Total deafness & $34(20)$ \\
\hline \multicolumn{2}{|l|}{ Contralateral ear } \\
\hline Normal hearing & $97(56)$ \\
\hline Abnormal hearing & $40(44)$ \\
\hline \multicolumn{2}{|l|}{ Tinnitus, additionally } \\
\hline Yes & $139(80)$ \\
\hline No & $34(20)$ \\
\hline \multicolumn{2}{|l|}{ Vertigo } \\
\hline Yes & $33(19)$ \\
\hline No & $140(81)$ \\
\hline \multicolumn{2}{|l|}{ Smoking } \\
\hline Yes & $24(14)$ \\
\hline No & $149(86)$ \\
\hline \multicolumn{2}{|l|}{ Charlson Comorbidity Index } \\
\hline Index $=0$ & $121(70)$ \\
\hline Index $=1$ & $27(16)$ \\
\hline Index = 2 & $19(11)$ \\
\hline Index $\geq 3$ & $6(4)$ \\
\hline \multicolumn{2}{|l|}{ Vascular risk profile } \\
\hline Yes & $93(54)$ \\
\hline No & $80(46)$ \\
\hline \multicolumn{2}{|l|}{ Metabolic syndrome } \\
\hline Yes & $4(2)$ \\
\hline No & $169(98)$ \\
\hline \multicolumn{2}{|c|}{ Final absolute hearing gain $(\triangle 6 \mathrm{PTA})$} \\
\hline $0 \mathrm{~dB}$ & $24(14)$ \\
\hline $1-19 \mathrm{~dB}$ & $110(64)$ \\
\hline \multirow[t]{2}{*}{$\geq 20 \mathrm{~dB}$} & $39(23)$ \\
\hline & Median, range \\
\hline Age (years) & $64,18-88$ \\
\hline Interval onset to therapy (days) & $3.5,0-28$ \\
\hline
\end{tabular}

Table 2 Patients' characteristics $(\mathbf{n}=173)$ (Continued)

\begin{tabular}{ll}
\hline Hearing loss, initial (6PTA; dB) & $42.5,14.2-110$ \\
Hearing loss, final (6 PTA; dB) & $30,0.8-105.8$ \\
Hearing gain, absolute ( $\triangle 6 \mathrm{PTA} ; \mathrm{dB})$ & $9,0-100$ \\
Hearing loss, contralateral ear, initial (6PTA) & $17.5,0-120$ \\
\hline
\end{tabular}

gender ratio was balanced ( $47 \%$ female and $53 \%$ male patients, respectively). There was no side predominance (53\% left and $47 \%$ right ear, respectively). Four of five patients complained also of tinnitus in the affected ear. Only $14 \%$ of patients were smokers. About two of three patients $(70 \%)$ had no relevant comorbidity according to Charlson comorbidity index but half of the patients showed cardiovascular risk factors.

Due to the 6PTA, the initial hearing loss was $50.6 \pm$ $27.2 \mathrm{~dB}$. The contralateral ear had a 6PTA of $21.2 \pm$ $15.7 \mathrm{~dB}$. The contralateral ear had a 6PTA of $<20 \mathrm{~dB}$, i.e. a normal hearing result, in $56 \%$ of the cases. Three patients were deaf on the contralateral ear. The interval between onset of hearing loss and begin of in-patient therapy was $5.7 \pm 6.1$ days. The average follow-up period, i.e. the time from first to last audiogram without further hearing improvement, was $51.0 \pm 44.9$ days (range: $10-$ 280 days).

\section{Overall recovery}

The absolute hearing gain between the initial audiogram and the final audiogram was $15.6 \pm 20.1 \mathrm{~dB}$. The mean relative hearing gain was $27.6 \pm 23.7 \%$. The mean relative hearing gain in relation to the contralateral side was $49.4 \pm 45.6 \%$. Eighty-one patients $(47 \%)$ had a final hearing gain of $\geq 10 \mathrm{~dB}$. Twenty-nine patients (17\%) had a relative hearing gain of $\geq 50 \%$. Seventy-two patients $(42 \%)$ had a relative hearing gain in relation to the contralateral side of $\geq 50 \%$.

\section{Prognostic impact of clinical and laboratory parameter}

An overview about the serology results at time of diagnosis is presented in Table 1. Blood parameters were very variable in the study sample. About half of the patients had elevated glucose values. About one third had elevated cholesterol and a about quarter elevated triglyceride values. One quarter showed a hyperfibrinogenemia.

The univariate analysis on prognostic factors for better outcome is summarized in Table 3. The following clinical parameters were significantly correlated to better outcome ( $\geq 10 \mathrm{~dB}$ absolute hearing gain): Low-frequency hearing loss had a better outcome than other audiogram patterns $(p<0.0001)$. Start of inpatient treatment $<4$ days after onset was better than a delayed treatment $\geq 4$ days after onset $(p=0.018)$. First SSNHL had a better outcome than recurrent SSNHL ( $p=0.001)$, and initial hearing loss $\geq 60 \mathrm{~dB}$ had a better outcome than an initial 


\section{Table 3 Prognostic influence of clinical and serologic parameters on hearing gain $(\triangle 6 \mathrm{PTA}) \geq 10 \mathrm{~dB}$ absolute hearing gain}

\begin{tabular}{|c|c|}
\hline Parameter & $\Delta 6 \mathrm{PTA}<>10 \mathrm{~dB} p$ \\
\hline Gender & 0.160 \\
\hline Age & 0.176 \\
\hline Side & 0.624 \\
\hline Tinnitus & 0.133 \\
\hline Vertigo & 0.574 \\
\hline Smoker & 0.586 \\
\hline Comorbidity (Charlson Index $\geq 1$ ) & 0.435 \\
\hline Vascular risk factor & 0.402 \\
\hline Low-frequency hearing loss & $<0.0001$ \\
\hline Start of inpatient treatment $<4$ days after onset & 0.018 \\
\hline Interval between first and last audiogram & 0.065 \\
\hline First SSNHL & 0.001 \\
\hline Contralateral ear with normal hearing & 0.159 \\
\hline Initial hearing loss $\geq 60 \mathrm{~dB}$ & $<0.0001$ \\
\hline aPTT, normal & 0.905 \\
\hline Quick, lower than normal & 0.040 \\
\hline Fibrinogen (g/l), high (hyperfibrinogenemia) & 0.007 \\
\hline Red-cell count (Tptl/I) women & 0.611 \\
\hline Red-cell count (Tptl/I) men & 0.593 \\
\hline Hemoglobin $(\mathrm{mmol} / \mathrm{l})$ women & 0.901 \\
\hline Hemoglobin (mmol/l) men & 0.946 \\
\hline Hematocrit women & 0.727 \\
\hline Hematocrit men & 0.086 \\
\hline White-cell count $(/ \mu l)$ & 0.433 \\
\hline Platelet count (Gpt/l) & 0.749 \\
\hline $\mathrm{MCH}$ & 0.456 \\
\hline $\mathrm{MCHC}$ & 0.445 \\
\hline MCV & 0.582 \\
\hline Glucose (mmol/l) & 0.078 \\
\hline Sodium (mmol/l) & 0.656 \\
\hline Potassium (mmol/l) & 0.164 \\
\hline Calcium (mmol/l) & 0.273 \\
\hline Urea (mmol/l) & 0.694 \\
\hline Creatinine $(I \mathrm{~mol} / \mathrm{l})$ women & 0.116 \\
\hline Creatinine $(I \mathrm{~mol} / \mathrm{l})$ men & 0.497 \\
\hline C-reactive protein (mg/l) & 0.380 \\
\hline Cholesterol (mmol/l) & 0.088 \\
\hline LDL (mmol/l) & 0.131 \\
\hline $\mathrm{HDL}(\mathrm{mmol} / \mathrm{l})$ & 0.922 \\
\hline $\mathrm{LDL} / \mathrm{HDL}$ & 0.367 \\
\hline Triglycerides (mmol/l) & 0.970 \\
\hline
\end{tabular}

$p$ values in bold are $p$ values below 0.05 , i.e. significant $p$ values. loss $<60 \mathrm{~dB}(p<0.0001)$. Two laboratory parameters had influence on the outcome: a quick value lower than the reference values $(p=0.040)$; and a hyperfibrinogenemia $(p=0.007)$.

Multivariate analysis revealed that first SSNHL $(p=0.004)$, start of inpatient treatment $<4$ days after onset $(p=0.015)$, initial hearing loss $\geq 60 \mathrm{~dB}(p=0.001)$, and hyperfibrinogenemia $(p=0.032)$ were independent prognostic factors for better hearing gain (Table 4).

\section{Discussion}

We analyzed 173 patients with unilateral SSNHL treated within four years with a standardized treatment protocol. Interested in predictors of the prognosis, we focused not only on clinical and audiological data like in several previous studies, but included also all laboratory values of clinical routine into the univariate and multivariate analysis. Interestingly, two serologic markers with influence on the rheology of the blood, a lower quick value $(<70 \%)$ and a hyperfibrinogenemia (fibrinogen $>3 \mathrm{~g} / \mathrm{l}$ ), were associated with better outcome.

In comparison to other studies, the observed median initial hearing loss was high with $42.5 \mathrm{~dB}$. Absolute median hearing gain after combined prednisolone plus pentoxiphylline therapy was low with $9 \mathrm{~dB}$. The relative hearing was $49 \%$. Including also only SSNHL of $\geq 30 \mathrm{~dB}$ and using carbogen inhalation and prednisone orally, Cvorovic et al. recently reported for 541 patients a $15.1 \mathrm{~dB}$ absolute hearing gain and a relative hearing gain of $47 \%$, i.e. in the range of the present study [5]. Using a comparable treatment regime in one study arm, a recent prospective trial reported an equivalent relative hearing gain of $43 \%$ [9]. A spontaneous hearing recovery rate without treatment for SSNHL of more than $25 \mathrm{~dB}$ and a relative hearing gain of $47-63 \%$ is reported [10-12]. We hypothesize that a negative selection bias is responsible for high initial hearing loss and the relative less pronounced hearing gain in the present study. First, only patients with sudden hearing loss of $\geq 30 \mathrm{~dB}$ were included. Second, inpatient treatment is mainly intended (and only covered by health insurance) in Germany if outpatient treatment fails to improve hearing within the first days after onset of SSNHL or if other symptoms like vertigo or severe hearing impairment on the contralateral side are existent. In the present study sample half of the patients had unsuccessful outpatient treatment before admission for inpatient treatment.

The two clinical factors: start of inpatient treatment $<4$ days after onset and first SSNHL were associated with better outcome. Furthermore, two audiological factors: lowfrequency hearing loss and initial hearing loss $\geq 60 \mathrm{~dB}$ were related to better outcome. These results are partly in accordance to previous studies. It has been shown that hearing recovery is greatest when corticosteroid treatment is 
Table 4 Multivariate binary logistic regression analysis on independent prognostic factors for better outcome measured as absolute hearing gain $\geq 10 \mathrm{~dB}$

\begin{tabular}{llllllll}
\hline Parameter & B & S.E. & Wald & $\boldsymbol{p}$ & Odds ratio & $\mathbf{9 5 \%} \mathbf{C l}$ lower & $\mathbf{9 5 \%}$ Cl upper \\
\hline First SSNHL & -1.280 & 0.445 & 8.291 & $\mathbf{0 . 0 0 4}$ & 3.597 & 1.506 & 8.621 \\
Low-frequency type & 1.238 & 0.692 & 3.205 & 0.073 & 3.450 & 0.889 & 13.389 \\
Quick lower than reference value & 0.388 & 0.669 & 0.337 & 0.562 & 1.474 & 0.397 & 5.469 \\
Fibrinogen high (hyperfibrinogenemia) & -0.967 & 0.451 & 4.595 & $\mathbf{0 . 0 3 2}$ & 2.631 & 1.086 & 6,369 \\
Interval between onset and therapy begin <4 days & 0.912 & 0.375 & 5.915 & $\mathbf{0 . 0 1 5}$ & 2.489 & 1.194 & 5.191 \\
Initial hearing loss $\geq 60 \mathrm{~dB}$ & -1.482 & 0.463 & 10.243 & $\mathbf{0 . 0 0 1}$ & 4.406 & 1.776 & 10.869 \\
\hline
\end{tabular}

$p$ values in bold are $p$ values below 0.05 , i.e. significant $p$ values.

started within the first 1-2 weeks after onset of SSNHL $[1,2,5,10]$. Many studies revealed that low-frequency losses do better than high-frequency losses $[5,10,13,14]$. More severe initial hearing loss has higher probability of improvement in some studies but in other studies a lower probability $[2,5,15]$. In contrast to others, in present study vertigo or impaired hearing on the contralateral ear had no negative prognostic influence $[2,5,3]$. The reason why vertigo had no influence in the present study might be that patients with acute vestibular deficits elicited by caloric testing were strictly excluded.

If at all of interest, laboratory investigations were mainly analyzed on their role as risk factors for SSNHL. For instance, hypercholesterolemia and hyperglycemia were observed more frequently in SSNHL patients than in control populations $[16,17]$. Consistent to that, we found a hypercholesterolemia in $38 \%$ and a hyperglycemia in $53 \%$ of the patients at the time of diagnosis (cf. Table 1). Only a few studies have analyzed the prognostic role of laboratory values on treatment outcome of SSNHL. In two older studies, in times when CRP was not yet part of routine blood examinations, an elevated erythrocyte sedimentation rate was correlated to better outcome $[2,10]$. In the present study CRP values had no influence on outcome. As CRP is accepted to be more sensitive and specific for acute inflammatory reactions [18], and observing increased CRP values only for $7 \%$ of the study sample, we state that acute inflammatory reaction or an underlying inflammatory disease, respectively, is not related to at least most cases of SSNHL and therefore does not play a prognostic role.

Univariate statistical analysis exposed that a decreased Quick test value $(<70 \%)$ at time of diagnosis was related to better hearing gain. The Quick prothrombin time test still is the basis for monitoring anticoagulant therapy in many countries worldwide [19]. Unfortunately, International normalized ratio (INR) values were not available for the majority of patients. INR values would have the advantage that the data would have been directly comparable to data from other laboratories. Seventeen $(10 \%)$ of the patients with SSNHL (initial hearing loss of these patients was $65.4 \pm 30.1 \mathrm{~dB} ; 7$ patients with initial loss $\geq 60 \mathrm{~dB}$ ) had a decreased Quick value because of anticoagulant therapy in accordance to anticoagulation guidelines for cardiac diseases, history of stroke, peripheral arterial disease, or venous thromboembolism. Only patients under anticoagulant therapy showed decreased Quick values. The anticoagulant therapy was sustained during treatment of SSNHL holding Quick values in the therapeutic range (data not shown). The antithrombotic effects of the anticoagulants decrease the viscosity of the plasma. We speculate that the combination of the SSNHL therapy with the anticoagulant therapy significantly improved the microcirculatory blood flow of the inner ear. In turn, this supports the theory that a vascular impairment with disturbance of the inner ear microcirculation is at least in some patients with SSNHL a causative factor [20,21].

Even more striking was the prognostic effect of fibrinogen at time of diagnosis on the hearing gain as this parameter remained also significantly relevant in the multivariate analysis. A quarter of patients had elevated fibrinogen values at time of SSNHL diagnosis. It has been widely accepted that hyperfibrinogenemia is an independent risk factor for cardiovascular diseases [2]. Fibrinogen is the substrate for thrombin and represents the final step in the coagulation cascade and is essential for platelet aggregation [22]. Furthermore, hyperfibrinogenemia seems to be a risk factor for SSNHL $[23,24]$. This was the basis to introduce fibrinogen apheresis as treatment option for SSNHL [9]. Recently, it has been shown in guinea pigs that acute hyperfibrinogenemia has a direct negative impact on the cochlear microcirculation [25]. We hypothesize that patients with hyperfibrinogenemia in the present study sample had a better outcome because a vascular factor/event triggered the SSNHL. The treatment regime used primarily was designed to improve the rheological blood performance with the aim to improve the cochlear microcirculation [26].

If fibrinogen is qualified to be a biomarker for treatment selection has to be proven by further prospective trials. In deployment of the assumption that SSNHL is an umbrella term for a disease with several causative factors, such biomarkers are needed at least to select patients with vascular origin of SSNHL as only these patients can profit optimally from vascular therapy regimes. 


\section{Conclusion}

The presented cohort study on 173 patients with SSNHL revealed that beside clinical and audiological factors also the laboratory markers: decreased Quick test value and a hyperfibrinogenemia were positive prognostic markers for better outcome using a treatment regime mainly intending to improve the cochlear microcirculation. Therefore, hyperfibrinogenemia is not only a risk factor for SSNHL but also a positive prognostic marker of outcome when using a rheological regime to treat SSNHL. Especially fibrinogen seems to be an interesting candidate as biomarker for better patient selection for treatment regimens of SSNHL focusing on the refinement of cochlear microcirculation.

\section{Abbreviations \\ SSNHL: Sudden sensorineural hearing loss; PTA: Pure tone audiometry; MCV: Mean corpuscular volume; MCH: Mean corpuscular hemoglobin; MCHC: Mean corpuscular hemoglobin concentration; CRP: C-reactive protein; LDL: Low density lipoprotein; HDL: High density lipoprotein; aPTT: Activated partial thromboplastin time; SD: Standard deviation; Min: Minimum; Max: Maximum; PPT: Partial thromboplastin time; Tpt/l: $10^{3}$ cells per liter; Gpt/I: $10^{9}$ cells per liter; BERA: Brainstem electrical response audiometry; MRI: Magnetic resonance imaging.}

\section{Competing interests}

There is no competing interest. The authors confirm that they do not have any financial relationship concerning this research.

The authors indicate that they have no a financial relationship with any organization or company mentioned in the manuscript. The research was not sponsored by a third party.

\section{Authors' contribution}

OGL and CW had the idea for the study. OGL and MK drafted the manuscript. JW performed the data collection. OGL and JW performed the statistical analysis. OGL designed tables and figures. All authors read and approved the final manuscript.

\section{Author details}

'Department of Otorhinolaryngology, Jena University Hospital, Lessingstrasse 2, Jena D-07740, Germany. ${ }^{2}$ Present address: Department of Otorhinolaryngology, University Giessen, Giessen, Germany. ${ }^{3}$ Institute of Clinical Chemistry and

Laboratory Diagnostics, Jena University Hospital, Jena, Germany.

Received: 12 September 2013 Accepted: 7 July 2014

Published: 9 July 2014

\section{References}

1. Stachler RJ, Chandrasekhar SS, Archer SM, Rosenfeld RM, Schwartz SR, Barrs DM, Brown SR, Fife TD, Ford P, Ganiats TG, Hollingsworth DB, Lewandowski CA, Montano JJ, Saunders JE, Tucci DL, Valente M, Warren BE, Yaremchuk $\mathrm{KL}$, Robertson PJ: Clinical practice guideline: sudden hearing loss. Otolaryngol Head Neck Surg 2012, 146(Suppl):S1-S35.

2. Byl FM Jr: Sudden hearing loss: eight years' experience and suggested prognostic table. Laryngoscope 1984, 94:647-661.

3. Egli Gallo D, Khojasteh E, Gloor M, Hegemann SC: Effectiveness of systemic high-dose dexamethasone therapy for idiopathic sudden sensorineural hearing loss. Audiol Neurootol 2013, 18:161-170.

4. Chau JK, Lin JR, Atashband S, Irvine RA, Westerberg BD: Systematic review of the evidence for the etiology of adult sudden sensorineural hearing loss. Laryngoscope 2010, 120:1011-1021.

5. Cvorovic L, Deric D, Probst R, Hegemann S: Prognostic model for predicting hearing recovery in idiopathic sudden sensorineural hearing loss. Otol Neurotol 2008, 29:464-469.

6. D'Hoore W, Sicotte C, Tilquin C: Risk adjustment in outcome assessment: the Charlson comorbidity index. Meth Inf Med 1993, 32:382-387.
7. Michel O: [The revised version of the german guidelines "sudden idiopathic sensorineural hearing loss"]. Laryngorhinootologie 2011, 90:290-293.

8. Plontke SK, Bauer M, Meisner C: Comparison of pure-tone audiometry analysis in sudden hearing loss studies: lack of agreement for different outcome measures. Otol Neurotol 2007, 28:753-763.

9. Suckfull M: Fibrinogen and LDL apheresis in treatment of sudden hearing loss: a randomised multicentre trial. Lancet 2002, 360:1811-1817.

10. Mattox DE, Simmons FB: Natural history of sudden sensorineural hearing loss. Ann Otol Rhinol Laryngol 1977, 86:463-480.

11. Probst R, Tschopp K, Ludin E, Kellerhals B, Podvinec M, Pfaltz CR: A randomized, double-blind, placebo-controlled study of dextran/pentoxifylline medication in acute acoustic trauma and sudden hearing loss. Acta Otolanyngol 1992, 112:435-443

12. Weinaug P: [How high is the rate of spontaneous healing of sudden deafness? Comments on the contribution "Spontaneous healing of sudden deafness"]. HNO 2001, 49:431-432. discussion 3.

13. Shaia FT, Sheehy JL: Sudden sensori-neural hearing impairment: a report of 1,220 cases. Laryngoscope 1976, 86:389-398.

14. Jun HJ, Chang J, Im GJ, Kwon SY, Jung H, Choi J: Analysis of frequency loss as a prognostic factor in idiopathic sensorineural hearing loss. Acta Otolaryngol 2012, 132:590-596.

15. Fetterman BL, Saunders JE, Luxford WM: Prognosis and treatment of sudden sensorineural hearing loss. American J Otol 1996, 17:529-536.

16. Aimoni C, Bianchini C, Borin M, Ciorba A, Fellin R, Martini A, Scanelli G, Volpato S: Diabetes, cardiovascular risk factors and idiopathic sudden sensorineural hearing loss: a case-control study. Audiol Neurootol 2010 15:111-115.

17. Cadoni G, Scorpecci A, Cianfrone F, Giannantonio S, Paludetti G, Lippa S: Serum fatty acids and cardiovascular risk factors in sudden sensorineural hearing loss: a case-control study. Ann Otol Rhinol Laryngol 2010, 119:82-88.

18. Osei-Bimpong A, Meek JH, Lewis SM: ESR or CRP? A comparison of their clinical utility. Hematol 2007, 12:353-357.

19. Jackson CM, Esnouf MP: Has the time arrived to replace the quick prothrombin time test for monitoring oral anticoagulant therapy? Clin Chem 2005, 51:483-485.

20. Lin RJ, Krall R, Westerberg BD, Chadha NK, Chau JK: Systematic review and meta-analysis of the risk factors for sudden sensorineural hearing loss in adults. Laryngoscope 2012, 122:624-635.

21. Ballesteros F, Tassies D, Reverter JC, Alobid I, Bernal-Sprekelsen M: Idiopathic sudden sensorineural hearing loss: classic cardiovascular and new genetic risk factors. Audiol Neurootol 2012, 17:400-408

22. Koenig W: Fibrin(ogen) in cardiovascular disease: an update. Thromb Haemost 2003, 89:601-609.

23. Suckfull M, Wimmer C, Reichel O, Mees K, Schorn K: Hyperfibrinogenemia as a risk factor for sudden hearing loss. Otol Neurootol 2002, 23:309-311.

24. Rudack C, Langer C, Stoll W, Rust S, Walter M: Vascular risk factors in sudden hearing loss. Thromb Haemost 2006, 95:454-461.

25. Ihler F, Strieth S, Pieri N, Göhring P, Canis M: Acute hyperfibrinogenemia impairs cochlear blood flow and hearing function in guinea pigs in vivo. Int J Audiol 2012, 51:210-215.

26. Michel O, Jahns T, Joost-Enneking M, Neugebauer P, Streppel M, Stennert E: [The Stennert antiphlogistic-rheologic infusion schema in treatment of cochleovestibular disorders]. HNO 2000, 48:182-188.

doi:10.1186/1472-6815-14-6

Cite this article as: Wittig et al:: Prognostic impact of standard laboratory values on outcome in patients with sudden sensorineural hearing loss. BMC Ear, Nose and Throat Disorders 2014 14:6. 